\title{
Antony Flew (2012-2013). Dios existe Antony Flew (2012-2013). God exists
}

Recibido: 04 de marzo de 2016 - Revisado: 12 de abril de 2016 - Aprobado: 02 de junio de 2016

Ceferino P. D. Muñoz ${ }^{1}$

Editorial: Trotta

Ciudad: Madrid

Páginas: 167

La existencia de Dios es una de esas constantes filosóficas que más ha ocupado a los grandes pensadores de todos los tiempos, tanto teístas como ateos, e incluso al interior de cada grupo en particular. Y esto se entiende toda vez que una auténtica meditación filosófica siempre de algún modo $u$ otro remata en la existencia de Dios y en su naturaleza, ya sea para negar o para afirmar tal existencia, pero nunca para soslayarla.

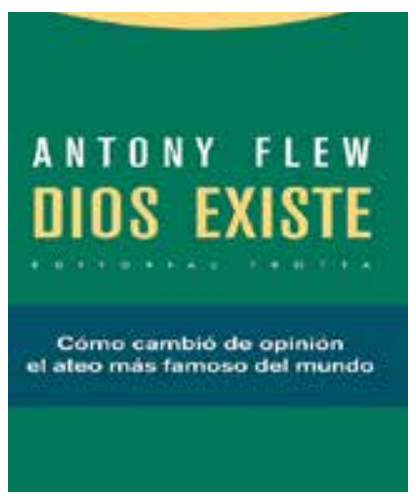

Un caso sumamente peculiar es el de Antony Flew (1923-2010), quien seguramente será recordado en la historia de la filosofía como uno de los intelectuales que hizo notables aportes para la elucidación de la cuestión.

En este sentido, el filósofo británico aparece como el teórico anglosajón que durante la segunda mitad del siglo $\mathrm{XX}$ brindó los argumentos más fuertes a favor del ateísmo, pero que hacia el final de su vida concluye que se había equivocado y que, contrariamente a lo que creyó y sostuvo por más de cincuenta años, hay suficientes pruebas filosóficas que muestran que Dios sí existe, es decir, que hay una inteligencia superior que fundó y que ordena el universo.

${ }^{1}$ Docente investigador en Consejo Nacional de Investigaciones Científicas y Técnicas, Universidad de Mendoza, Mendoza, Argentina. Correo electrónico: ceferinomm@hotmail.com

Para citar esta reseña use: Muñoz, C. (2016). Antony Flew (2012-2013) Dios existe. Civilizar Ciencias Sociales y Humanas, 16(31), 281-284. 
Pues bien, este es el asunto del último libro de Antony Flew, escrito en colaboración con Roy Abraham Varghese. El ejemplar está compuesto por un prólogo, un prefacio, una introducción, dos partes centrales (integradas por tres y siete capítulos respectivamente) y dos apéndices. El cuidadísimo y orientador prólogo estuvo a cargo de Francisco Soler Gil; allí el prologuista -entre otros datos por demás pertinentes-habla deunestilo Flew para referirse a un modo de argüir, o más precisamente a un código de conducta argumentativa, que sería el que debiera respetar todo el que se haga llamar filósofo y que lamentablemente muchos de los colegas de Flew no respetaron al enterarse del cambio de postura del pensador inglés.

Por su parte, Roy Abraham Varghese redactó el prefacio. Varghese recalca el ataque feroz que recibió Flew a causa de su cambio de posición, al tiempo que refiere las características del positivismo lógico - con quien Flew había roto relaciones en su momento-y el papel troncal que cumple en este la famosa verificación, donde solo tienen sentido las proposiciones provenientes de las ciencias empíricas, la lógica o la matemática, y donde la afirmación "Dios existe" no significa nada. Así mismo, el autor del prefacio se centra en la figura intelectual de Flew y en su contribución a la filosofía de la religión, destacando la cantidad y calidad de sus publicaciones, llegando a afirmar que en los últimos cien años no ha habido filósofo que se caracterice por la exposición sistemática, original, omniabarcadora e influyente como la ofrecida por el filósofo anglosajón.

La introducción fue compuesta por el mismo Flew, que deja claro a sus otrora correligionarios y hoy vehementes detractores que su cambio de postura se debe a motivos estrictamente racionales: "Quede constancia, pues, de que deseo silenciar todos esos rumores que me presentan haciendo apuestas pascalianas" (p. 36). Flew muy sintéticamente dice que puesto que el libro trata sobre los motivos de su cambio de posición sobre la existencia de Dios, espontáneamente el lector podría preguntarse en qué creía antes del cambio y por qué. Por ello los tres primeros capítulos explican esto último, mientras que los siete restantes refieren al descubrimiento de eso que Flew escribe con mayúsculas: lo Divino.

En este orden de ideas, el libro en cuestión tiene como eje principal el itinerario intelectual de Flew que acaba con su particular conversión, lo cual transforma a esta obra en un verdadero testamento filosófico. No obstante, el texto tiene un rigor que asombra en diversos sentidos: a) en cada una de las argumentaciones que se suceden, b) en la armonía que Flew logra establecer entre la filosofía y los últimos avances científicos, c) en cómo el autor consigue dejar al descubierto argumentos que poseen cierto barniz de racionalidad -y que en los círculos intelectuales suelen tenerse como premisas incuestionables-, pero que cuando a tales argumentos se les exigen razones de peso muestran su endeblez y d) en las discusiones e intercambios con pensadores que ya por esos años gozaban de una reconocida trayectoria y que aún hoy resuenan en los ámbitos académicos: Swinburne, Copleston, Warren, Craig, Plantinga, Alston, Mavrodes, Kenny, Schroeder, McInerny, etc.

Entre esos diálogos está el que mantuvo con el obispo Wright (Anexo B), el cual según nuestro autor aporta el mejor alegato que ha escuchado en favor del cristianismo: "Me impresiona mucho la argumentación del obispo Wright, que es totalmente fresca. Presenta las razones del cristianismo con un acento nuevo [...]. Es una argumentación absolutamente magnífica, radical y poderosa" (p. 167). Y en esta dirección hay algo que creemos debe destacarse, a saber: si bien Flew llega con sus razonamientos a la existencia de un Dios aristotélico, al mismo tiempo se muestra totalmente abierto a creer en una revelación:

¿Es posible que haya o haya habido una revelación divina? Como dije, no se pueden 
limitar las posibilidades de la omnipotencia, excepto en lo que se refiere a producir lo lógicamente imposible. Todo lo demás está abierto a la omnipotencia (p. 167).

Ahora bien, para nuestro autor, sí hubo tal revelación divina, la religión verdadera es el cristianismo; es decir, la creencia en que Dios se hizo hombre en la persona de Jesucristo: "Si esperamos que la Omnipotencia ponga en pie una religión, el cristianismo es el candidato con mejores credenciales" (p. 151).

Para concluir, mencionamos lo que quizá para algunos es un dato que puede pasar inadvertido en la lectura del libro: Flew durante sus años de estudiante en Oxford asistió al Socratic Club, cuyo presidente era el reconocido escritor converso C. S. Lewis, quien para Flew fue el más grande y eficaz apologista cristiano del siglo XX. El principio que daba vida a dicho foro de debate era ni más ni menos que aquel que Platón atribuye en la República a Sócrates: "debemos seguir la argumentación hasta dondequiera que nos lleve".

Pues bien, Flew sin dudas fue un filósofo que hizo honor a la máxima socrática, tanto que él mismo no deja de asombrarse cuando afirma: "[...] quizás nadie ha quedado tan sorprendido como yo mismo de que mi exploración de lo Divino, después de todos estos años, haya girado finalmente de la negación al descubrimiento" (p. 52). Y aquí para nosotros se torna patente en la vida intelectual de Antony Flew el antiguo dictum que sostiene que aquellos que son fieles a la verdad que conocen seguramente serán merecedores de la que aún ignoran. 
